From the Institute of Hematology and Institute of Pathological Anatomy, Catholic University S. Cuore, Rome, Italy; University Medical Center Utrecht, Utrecht; and Radboud University Nijmegen Medical Center, Nijmegen, the Netherlands.

Submitted December 15, 2009; accepted March 2, 2010; published online ahead of print at www.jco.org on April 20, 2010

Supported by Grant No. 4995 from Associazione Italiana per la Ricerca sul Cancro and Grant No. 7020068 from Fondi d'Ateneo, Linea D1, Università Cattolica del Sacro Cuore. M.G. was supported by Fondazione RomaProgetto Cellule Staminali. G.M. was supported by the Italian Society of Experimental Hematology.

Authors' disclosures of potential conflicts of interest and author contributions are found at the end of this article.

Corresponding author: Stefan Hohaus, $M D$, Istituto di Ematologia, Università Cattolica S. Cuore-Roma, L.go A Gemelli, 1, Rome, Italy 00168; e-mail: stefan.hohaus@rm.unicatt.it.

(c) 2010 by American Society of Clinical Oncology

0732-183X/10/2815-2538/\$20.00

DOI: $10.1200 / J C O .2009 .27 .6873$

\title{
Anemia in Hodgkin's Lymphoma: The Role of Interleukin-6 and Hepcidin
}

Stefan Hohaus, Giuseppina Massini, Manuela Giachelia, Barbara Vannata, Valentina Bozzoli, Annarosa Cuccaro, Francesco D'Alo', Luigi Maria Larocca, Reinier A.P. Raymakers, Dorine W. Swinkels, Maria Teresa Voso, and Giuseppe Leone

\section{$\begin{array}{lllllllll}\text { A } & \text { B } & \text { S } & \text { T } & \text { R } & \text { A } & \text { C } & \text { T }\end{array}$}

\section{Purpose}

Cytokines play a pivotal role in Hodgkin's lymphoma (HL). Because interleukin-6 (IL-6) induces expression of hepcidin, one of the principal regulators of iron metabolism, we studied the contribution of hepcidin in anemia in HL at diagnosis.

\section{Patients and Methods}

Plasma samples from 65 patients with HL were analyzed for hepcidin levels using a combination of weak cation exchange chromatography and time-of-flight mass spectrometry; cytokine levels were analyzed using enzyme-linked immunosorbent assays and parameters of iron metabolism and acute-phase reaction.

\section{Results}

Hepcidin plasma levels were significantly higher in HL patients when compared with controls, independent of the presence of anemia $(P=.001)$. In the subset of patients with anemia, hepcidin levels inversely correlated with hemoglobin levels $(P=.01)$. Analyzing parameters of iron metabolism, hepcidin levels showed a positive correlation with ferritin $(P<.001)$ and an inverse correlation to iron and iron-binding capacity. Hepcidin strongly correlated to IL-6 levels $(P<.001)$ but not to IL-10 or thymus and activation-regulated cytokine (TARC)/chemokine (C-C motif) ligand 17 (CCL17) levels. In a multivariate regression analysis, IL-6 and fibrinogen levels were independently associated with hepcidin. Higher hepcidin levels were observed in patients with more aggressive disease characteristics: stage IV disease $(P=.01)$, presence of B symptoms $(P=.03)$, and International Prognostic Score $>2(P=.005)$.

\section{Conclusion}

Our findings suggest that in $\mathrm{HL}$, hepcidin is upregulated by IL-6. Elevated hepcidin levels result in iron restriction and signs of anemia of chronic inflammation, although hepcidin-independent mechanisms contribute to development of anemia in $\mathrm{HL}$.

\section{J Clin Oncol 28:2538-2543. (C) 2010 by American Society of Clinical Oncology}

\section{INTRODUCTION}

Anemia is a presenting symptom in approximately $40 \%$ of patients with Hodgkin's lymphoma (HL). It is more frequently observed in advanced stages and is usually associated with B symptoms such as fever, night sweats, and weight loss. In general, the anemia is normochromic and normocytic and is usually mild, with hemoglobin $(\mathrm{Hb})$ levels between 10 and $12 \mathrm{~g} / \mathrm{dL}$.

The anemia of chronic disease is seen in a wide variety of inflammatory states including acute systemic inflammatory response syndrome, chronic infections, inflammatory disorders, and some cancers. ${ }^{1,2}$ This iron-refractory anemia is characterized by low serum iron (hypoferremia), reduced ironbinding capacity, and subnormal transferrin satura- tion, while bone marrow iron is relatively preserved. Traditional biochemical iron indicators (eg, serum iron, ferritin, transferrin saturation) are of only limited use because of the distorting effects of inflammation on their levels. Serum ferritin levels, although useful indicators of iron status in patients without underlying chronic disorders, increase in patients with inflammatory diseases. Ferritin levels have been reported to be elevated in patients with $\mathrm{HL}$, in particular in advanced stages and during disease progression. ${ }^{3,4}$

Studies in humans and mice suggest that the iron-regulatory hormone hepcidin is the principal mediator of anemia of chronic disease and/ or inflammation. ${ }^{5-11}$ Hepcidin is a liver-produced acute-phase peptide whose overproduction leads to iron-limited erythropoiesis. Hepcidin binds to the 
cell membrane iron exporter ferroportin and induces its internalization and degradation, thus decreasing iron release from macrophages and enterocytes. Inflammatory cytokines increase the expression of hepcidin, ${ }^{12,13}$ leading to decreased absorption of iron from the intestine, and block the release of iron from the reticuloendothelial system and the liver. ${ }^{14}$ Infusion of interleukin-6 (IL-6) in human volunteers resulted in increased excretion of urinary hepcidin and development of hypoferremia. ${ }^{12}$ IL-6 is a potent inducer of hepcidin expression through a signal transducer and activator of transcription 3-dependent transcriptional mechanism. ${ }^{15-17}$ In addition, macrophages express hepcidin in response to microbial stimulation. ${ }^{18} \mathrm{~A}$ pathogenic cascade for the development of anemia of inflammation has been proposed that leads from IL-6 to hepcidin to hypoferremia and, as a consequence, to anemia of inflammation. ${ }^{7}$

The inflammatory response surrounding the Hodgkin's and Reed-Sternberg cell is part of HL as the cell of origin itself. In the interactions between the neoplastic Hodgkin's and Reed-Sternberg cells and the reactive cells of the microenvironment, there are high levels of cytokines, such as IL-6, IL-10, and the chemokine thymus and activation-regulated cytokine (TARC) among others. ${ }^{19}$ Local production of these cytokines results in elevated systemic levels in the peripheral blood, and these cytokines are responsible for the development of systemic symptoms and laboratory abnormalities that are correlated with disease prognosis. ${ }^{20-22}$ IL-6 is among the cytokines most strongly associated with anemia. ${ }^{20}$ We were interested in the contribution of hepcidin to the pathogenesis of anemia of HL and its relation to other cytokines important in the biology of the disease, including IL-6, IL-10, and TARC.

\section{PATIENTS AND METHODS}

\section{Patient Characteristics}

Our analysis included 65 patients (median age, 35 years; range 15 to 83 years; 36 females and 29 males) diagnosed with HL between March 2004 and May 2009 and observed at the Institute of Hematology of the Catholic University of Rome. Thirteen patients had stage IV disease, but only five patients showed bone marrow infiltration. Of these five patients, four patients were anemic, but only one patient had signs of reduced hematopoiesis as a result of bone marrow infiltration. Additional patient characteristics, including the International Prognostic Score (IPS), ${ }^{23}$ are detailed in Table 1. Peripheral blood samples were obtained at the time of initial diagnosis, and samples were collected early in the morning. All parameters of iron metabolism were determined in the central laboratory of the Catholic University. A group of 24 healthy individuals (median age, 41 years; range 18 to 63 years; 13 females, 11 males) was used as a control. ${ }^{24}$ Informed consent was obtained from patients and controls according to institutional guidelines, and blood sample collection was approved by our institutional ethical committee.

\section{Enzyme-Linked Immunosorbent Assay for Plasma Levels of IL-6, IL-10, and TARC}

IL-6, IL-10, and TARC levels were determined in pretreatment plasma samples, which had been stored at $-70^{\circ} \mathrm{C}$ and thawed for the first time, by a sandwich enzyme-linked immunosorbent assay, according to the manufacturer's instructions (Human IL-10 DuoSet and Human CCL17/TARC DuoSet, R\&D Systems, Minneapolis, MN; Human IL-6 US, BioSource International, Camarillo, CA).

\section{Hepcidin-25 Quantification}

Plasma hepcidin measurements were performed in July 2009 (testing laboratory: Hepcidinanalysis.com, Nijmegen, the Netherlands) by a combination of weak cation exchange chromatography and time-of-flight mass spectrometry (TOFMS). An internal standard (synthetic hepcidin-24; Peptide

\begin{tabular}{|c|c|c|c|c|c|c|c|c|c|}
\hline \multirow[b]{2}{*}{ Variable } & \multirow{2}{*}{$\begin{array}{l}\text { No. of } \\
\text { Patients }\end{array}$} & \multicolumn{2}{|c|}{$\begin{array}{l}\text { Hemoglobin } \\
\quad(n=65)\end{array}$} & \multicolumn{2}{|c|}{$\begin{array}{l}\text { Hepcidin } \\
(\mathrm{n}=59)\end{array}$} & \multicolumn{2}{|c|}{$\begin{array}{c}\text { IL-6 } \\
(n=55)\end{array}$} & \multicolumn{2}{|c|}{$\begin{array}{c}\text { TARC } \\
(n=57)\end{array}$} \\
\hline & & $\mathrm{g} / \mathrm{dL}$ & $P$ & $\mathrm{nmol} / \mathrm{L}$ & $P$ & $\mathrm{ng} / \mathrm{mL}$ & $P$ & $\mathrm{ng} / \mathrm{mL}$ & $P$ \\
\hline Age, years & & & .02 & & .03 & & .05 & & .98 \\
\hline$<45$ & 43 & 12.4 & & 6.5 & & 0.7 & & 3,575 & \\
\hline$>45$ & 22 & 11.2 & & 10.4 & & 4.1 & & 4,529 & \\
\hline Sex & & & .001 & & .06 & & .5 & & .02 \\
\hline Female & 36 & 11.3 & & 6.9 & & 2.1 & & 5,223 & \\
\hline Male & 29 & 12.9 & & 9.4 & & 1.3 & & 2,271 & \\
\hline Stage & & & .04 & & .01 & & .02 & & .37 \\
\hline$|-|||$ & 50 & 12.4 & & 6.3 & & 0.6 & & 3,671 & \\
\hline IV & 13 & 10.8 & & 13.7 & & 5.4 & & 3,434 & \\
\hline B symptoms & & & $<.001$ & & .03 & & .003 & & .07 \\
\hline No & 40 & 12.8 & & 5.9 & & 0.6 & & 2,999 & \\
\hline Yes & 23 & 10.9 & & 10.4 & & 2.1 & & 5,829 & \\
\hline Bulky disease & & & .21 & & .85 & & .32 & & .04 \\
\hline No & 46 & 12.3 & & 7.8 & & 1.2 & & 3,033 & \\
\hline Yes & 17 & 11.5 & & 7.2 & & 0.6 & & 6,806 & \\
\hline IPS* & & & $<.001$ & & .005 & & .002 & & .59 \\
\hline Low-risk & 49 & 12.7 & & 6.2 & & 0.6 & & 4,045 & \\
\hline High-risk & 14 & 9.9 & & 12.2 & & 3.0 & & 3,444 & \\
\hline
\end{tabular}

NOTE. $P$ values were determined by Mann-Whitney rank sum test.

Abbreviations: IL-6, interleukin-6; TARC, thymus and activation-regulated cytokine; IPS, International Prognostic Score.

${ }^{*}$ The IPS was calculated according to Hasenclever and Diehl. ${ }^{23}$ IPS scores 0-2 were considered as low-risk and $\geq 3$ as high-risk.

International, Louisville, KY) was used for quantification (www.hepcidinanalysis.com). ${ }^{25,26}$ Peptide spectra were generated on a Microflex LT matrixenhanced laser desorption/ionisation TOFMS platform (Bruker Daltonics, Billerica, MA). Plasma hepcidin-25 concentrations were expressed as $\mathrm{nmol} / \mathrm{L}$. The lower limit of detection of this method was $0.5 \mathrm{nmol} / \mathrm{L}$; average coefficients of variation were $2.7 \%$ (intrarun) and $6.5 \%$ (interrun). The median reference level of plasma hepcidin-25 is $4.2 \mathrm{nmol} / \mathrm{L}$ (range, 0.5 to $13.9 \mathrm{nmol} / \mathrm{L}$ ). ${ }^{24}$

\section{Statistical Analysis}

Wilcoxon signed rank test was used for two-sample comparisons of hepcidin plasma levels between patient and control groups or according to dichotomized patient characteristics. Comparisons between controls and patients were also performed using analysis of covariance models including sex, age, and ferritin levels as covariates. Since the distribution of plasma parameters in our population revealed a departure from normality that was mitigated using a logarithmic transformation, the log of the concentration was used for testing purposes. However, untransformed values were used for reporting results. Plasma parameters were analyzed both as continuous variables following logarithmic transformation and as dichotomous variables using the upper limit of normal of controls as a cutoff point. Correlations between the various blood parameters were calculated by linear regression models. A multivariate logistic regression model was used to examine the relationship between the dependent variable (hepcidin plasma level) and potential predictor variables, including $\mathrm{Hb}$, IL-6, ferritin, and fibrinogen levels. Stepwise backward elimination of nonsignificant parameters was used to obtain the best model. Computations were performed using STATA 10.0 software (STATA, College Station, TX).

\section{RESULTS}

\section{Anemia and Patient Characteristics in $\mathrm{HL}$}

We studied 65 patients with HL at diagnosis. Anemia, defined as $\mathrm{Hb}$ concentration $<12 \mathrm{~g} / \mathrm{dL}$, was present in 30 patients, and it was 
mild (Hb between 10 and $12 \mathrm{~g} / \mathrm{dL}$ ) in 20 patients. Anemia was normocytic and normochromic in 19 patients, while it was microcytic in 11 patients. Associations of anemia with patient characteristics are presented in Table 1. As expected, $\mathrm{Hb}$ concentration was lower in female patients, in patients older than age 45 years, and in patients with B symptoms, stage IV disease, and a higher IPS score $(>2)$.

\section{Hepcidin Levels and Anemia in HL Patients}

Hepcidin levels in 59 patients were determined in plasma samples taken at diagnosis by using a combination of weak cation exchange chromatography and TOFMS. The mean hepcidin level in HL patients was $7.9 \mathrm{nmol} / \mathrm{L}$, ranging from below the detection limit of 0.5 $\mathrm{nmol} / \mathrm{L}$ in three patients to $27.4 \mathrm{nmol} / \mathrm{L}$, and was significantly higher than that of a group of 24 non-anemic normal controls (mean, 2.77 nmol/L; range, 0.5 to $8.2 \mathrm{nmol} / \mathrm{L} ; P=.001$ ). The difference between HL patients and controls remained significant after including age and sex and adjusting for ferritin levels $(P=.002)$, which may influence hepcidin levels in healthy controls. Strikingly, when comparing controls with non-anemic HL patients, hepcidin was still significantly higher in $\mathrm{HL}(P=.02$; Fig 1$)$.

Patients older than age 45 years had higher hepcidin levels $(P=.03)$, and there was a borderline significance for higher hepcidin levels in males compared with females $(P=.06$; Table 1$)$. In anemic patients, hepcidin levels inversely correlated with $\mathrm{Hb}$ values $(r=-0.43 ; P=.02$; Fig 2$)$, while there was no correlation in the absence of anemia.

\section{Hepcidin and Iron Metabolism in $\mathbf{H L}$}

Data on iron metabolism were available for 39 patients. The median serum iron and total iron-binding capacity in HL patients

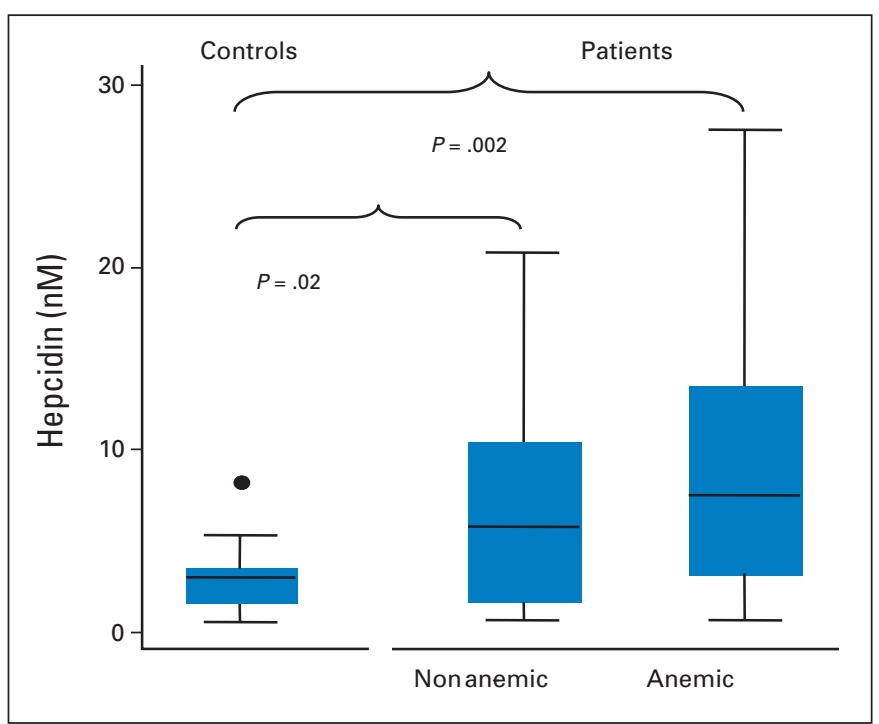

Fig 1. Box plots of hepcidin plasma concentrations in healthy controls ( $n=24$ ) and patients with Hodgkin's lymphoma $(H L)$ at diagnosis $(n=59)$. Patients with $\mathrm{HL}$ were divided into a non-anemic group with hemoglobin levels $>12 \mathrm{~g} / \mathrm{dL}$ $(\mathrm{n}=30)$ and an anemic group with hemoglobin levels $<12 \mathrm{~g} / \mathrm{dL}(\mathrm{n}=29)$. The upper border of the box indicates the upper quartile (75th percentile), while the lower border indicates the lower quartile (25th percentile), and the horizontal line in the box indicates the median. The vertical lines are the whiskers indicating the upper and lower adjacent values. Both anemic and non-anemic patients had significantly higher levels of hepcidin when compared with controls $(P=.002$ and 02 , respectively), while the difference between anemic and non-anemic patients was not statistically significant $(P=.18)$.

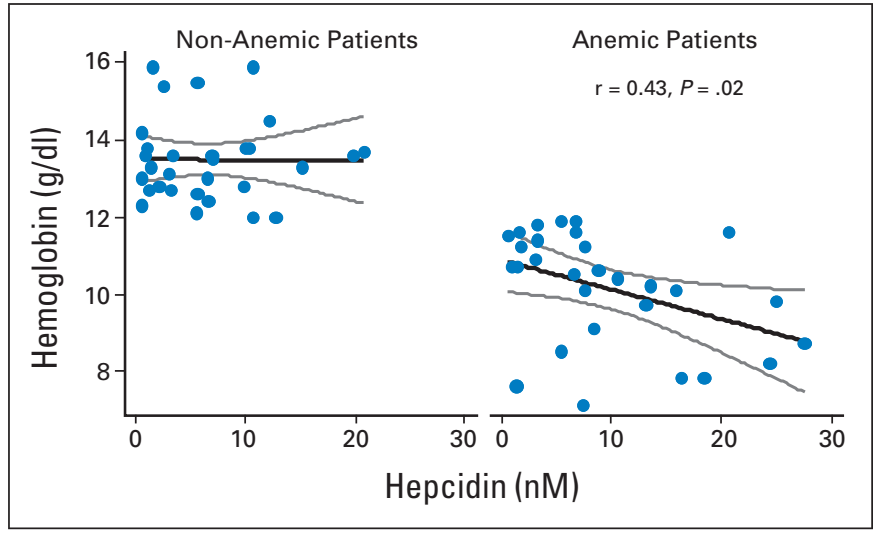

Fig 2. Correlation between hemoglobin and hepcidin in Hodgkin's lymphoma (HL) patients. Scatter plots with linear regression lines (black lines) and $95 \% \mathrm{Cls}$ (gray lines) showing significant inverse correlation between hemoglobin and hepcidin levels in anemic HL patients ( $r=-0.43 ; P=.02)$ but not in non-anemic patients $(r=0.04 ; P=.8)$.

were $33 \mu \mathrm{g} / \mathrm{dL}$ (range, 9 to $183 \mu \mathrm{g} / \mathrm{dL}$ ) and $233 \mu \mathrm{g} / \mathrm{dL}$ (range, 154 to $366 \mu \mathrm{g} / \mathrm{dL}$ ), respectively, and were lower than the normal range (40 to $150 \mu \mathrm{g} / \mathrm{dL}$ for iron and 250 to $425 \mu \mathrm{g} / \mathrm{dL}$ for total iron-binding capacity). Ferritin levels showed a wide variation with a median of 90 $\mathrm{ng} / \mathrm{mL}$ and a range between 7 and 7,500 ng/mL. Only three patients had iron deficiency anemia, defined by $\mathrm{Hb}$ levels $<12 \mathrm{~g} / \mathrm{dL}$ and microcytosis and ferritin levels $<12 \mathrm{ng} / \mathrm{mL}$.

Looking at parameters of iron metabolism, there was a strong correlation between hepcidin and ferritin $(r=0.62 ; P<.001)$ and an inverse correlation with iron and iron-binding capacity $(r=-0.42$, $P=.009$; and $r=-0.43, P=.02$, respectively; Fig 3 ). After adjustment for multiple testing, the correlation between hepcidin and parameters of iron metabolism, but not iron itself, maintained statistical significance (Table 2).

\section{Correlation of Hepcidin With Levels of IL-6 and Other Markers of Inflammation}

Because hepcidin is an acute-phase reactant during infection and/or inflammation, we examined the relationship between hepcidin and inflammatory cytokines and other proteins of the acute-phase reaction. Among these, ferritin, as described above, and fibrinogen correlated with hepcidin (Table 2).

IL-6 concentration was studied in 55 patients. It was below the detection limit of the assay $(0.01 \mathrm{ng} / \mathrm{mL})$ in 15 patients, while the mean concentration was $2.4 \mathrm{ng} / \mathrm{mL}$ ( $\pm 6.15 \mathrm{ng} / \mathrm{mL}$ ) in the remaining 40 patients. IL- 6 correlated with several laboratory parameters and clinical characteristics as detailed in Tables 1 and 2. In particular, IL-6 inversely correlated with $\mathrm{Hb}$ values $(r=-0.49 ; P<.001)$. We found a highly significant correlation between levels of hepcidin and IL-6 $(r=0.55 ; P<.001 ;$ Fig 4$)$, whereas there was no significant correlation with IL-10 or TARC levels, arguing against a role for these cytokines in hepcidin upregulation in HL patients.

Because several parameters indicative for anemia of inflammation were associated with hepcidin levels, we next performed a multivariate analysis to predict hepcidin levels. We included $\mathrm{Hb}$ values and the significant parameters from univariate analysis (Table 2): IL-6 as the most relevant cytokine, ferritin as the most important parameter for iron metabolism, and fibrinogen levels as the parameter for acutephase reaction. Using a stepwise backward regression analysis, $\mathrm{Hb}$ and 


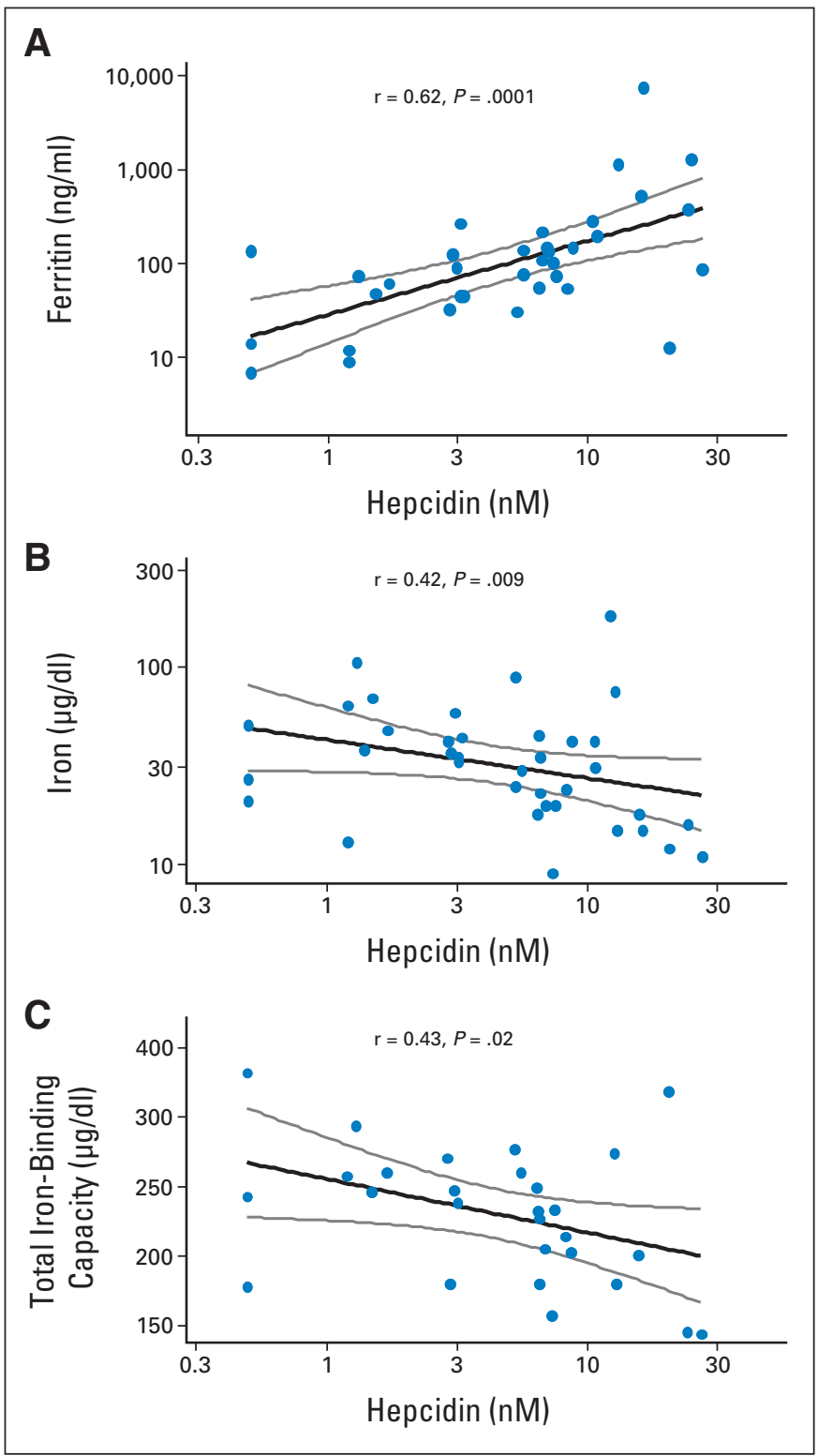

Fig 3. Correlations between hepcidin and parameters of iron metabolism. Scatter plots with linear regression (black lines) and 95\% Cls (gray lines) show significant correlations between hepcidin and (A) ferritin, $(B)$ iron, and (C) total iron-binding capacity.

ferritin levels were excluded, while IL-6 and fibrinogen independently correlated with hepcidin ( $P=.03$ and $P=.001$, respectively). Rerunning the model with only IL- 6 and fibrinogen confirmed the results obtained by the backward selection technique (Appendix Table A1, online only).

\section{Hepcidin and Clinical Characteristics}

We analyzed for associations of hepcidin levels with clinical characteristics with known prognostic impact. Higher hepcidin levels were observed in patients with stage IV disease $(P=.01)$, in the presence of B symptoms $(P=.03)$, and in patients with an IPS score $\geq 3(P=.005$; Table 1).

\section{DISCUSSION}

Our study shows that hepcidin plasma levels are increased in patients with HL. Hepcidin levels strongly correlate with changes typical for inflammation and Hodgkin's disease activity, such as increased IL-6 levels. Increased hepcidin was also found in non-anemic patients, whereas in anemic patients, there was a striking inverse correlation with the severity of anemia. It correlated with changes in iron metabolism that are typical for inflammation and acute-phase reaction, such as elevated ferritin, lower iron, reduced total iron-binding capacity, and higher fibrinogen levels. This is in line with the role of hepcidin as a gatekeeper for iron homeostasis, inhibiting the cellular efflux of iron through ferroportin, resulting in iron being trapped in macrophages and iron-absorbing enterocytes and reducing the availability of iron for erythropoiesis.

Iron redistribution is a hallmark of anemia of chronic disease. Although some cases of anemia can be attributed to iron deficiency, in our case series, there were only three patients with iron-deficiency anemia; the vast majority of patients with HL who are anemic present with anemia of chronic disease. Bone marrow infiltration as a confounding factor for development of anemia is rare in HL and was present in only five patients in our case series, with only one patient having extensive bone marrow infiltration in the biopsy that could explain anemia.

Given its high prevalence, anemia in HL is an interesting model for studying cytokine-mediated anemia. Experiments in mice and clinical observations have demonstrated that anemia of chronic disease is characterized by a complex interaction between the components of inflammation and indicate that IL- 6 seems to be the principal cytokine inducing iron-restricted erythropoiesis and anemia. ${ }^{2,12,27-30}$ IL-6 knockout mice fail to produce hepcidin in response to inflammatory challenges. ${ }^{12,27}$ During inflammation, IL-6 alone can rapidly induce hepcidin synthesis and corresponding hypoferremia. ${ }^{12}$ In a patient presenting with hemochromatosis and an auto-inflammatory disease, there was clear evidence for the IL-6-hepcidin axis in the development of hypoferremia and anemia of inflammation. ${ }^{31}$ In cell culture experiments, IL-6, but not IL-1 or tumor necrosis factor alpha (TNF- $\alpha$ ), induced hepcidin mRNA expression in human hepatocytes. ${ }^{32}$ In myeloma patients, plasma IL- 6 could induce hepcidin while no effects for TNF- $\alpha$ or interleukin- 1 beta (IL- $1 \beta$ ) were observed. ${ }^{29}$ In this line, we observed a strong association between IL- 6 and hepcidin in HL, while IL-10 or TARC did not play a significant role.

Because IL-6 levels more strongly correlated with development of anemia than hepcidin levels did, other IL-6-associated mechanisms than hepcidin-mediated iron restriction are also probably involved in the induction of anemia in HL. Administration of recombinant human IL-6 induces a rapid-onset, dose-dependent, progressive anemia that is quickly reversible after the cessation of therapy, with the characteristics of a dilutional anemia driven by marked increases in plasma volume. ${ }^{33,34}$ Impairment of proliferation and differentiation of erythroid progenitors could also contribute to IL-6-mediated anemia. IL-6 itself does not suppress erythropoiesis and has no demonstrable direct effect on the proliferation of hematopoietic progenitors. ${ }^{35}$ It is even a potent megakaryopoietic growth factor and may be the humoral mediator of reactive thrombosis accompanying inflammatory states. Suppression of erythropoiesis may be due to other acute-phase 


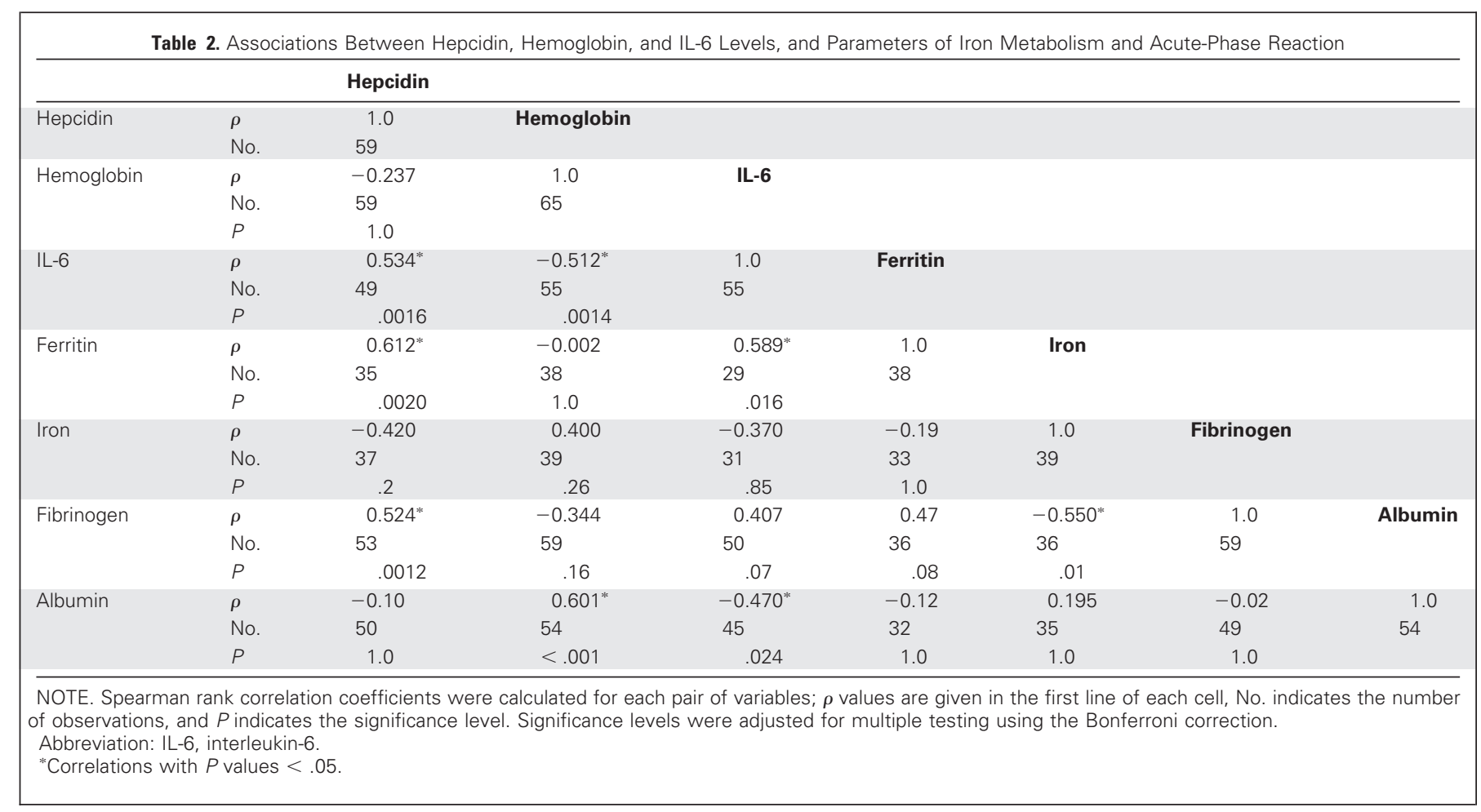

reactants induced by IL-6. Reduced expression of transferrin receptors, impaired binding affinity of transferrin receptors, and inadequate erythropoietin production and response may contribute to the defect of erythropoiesis in the anemia of chronic disease. ${ }^{2,36-38}$

Hepcidin levels were higher in HL patients with advanced-stage disease and B symptoms. A similar association of elevated hepcidin levels with advanced-stage disease has been reported for patients with non-Hodgkin's lymphoma and myeloma. ${ }^{29,39}$ Moreover, Ukarma et $\mathrm{al}^{39}$ observed higher hepcidin levels in anemic patients with hematologic tumors than with solid tumors. The association of hepcidin with unfavorable prognostic factors in our HL study raises the question of whether hepcidin may have a role as a biomarker. Anemia and IL-6 levels are well-known prognostic markers in $\mathrm{HL},{ }^{20,23,40,41}$ and future

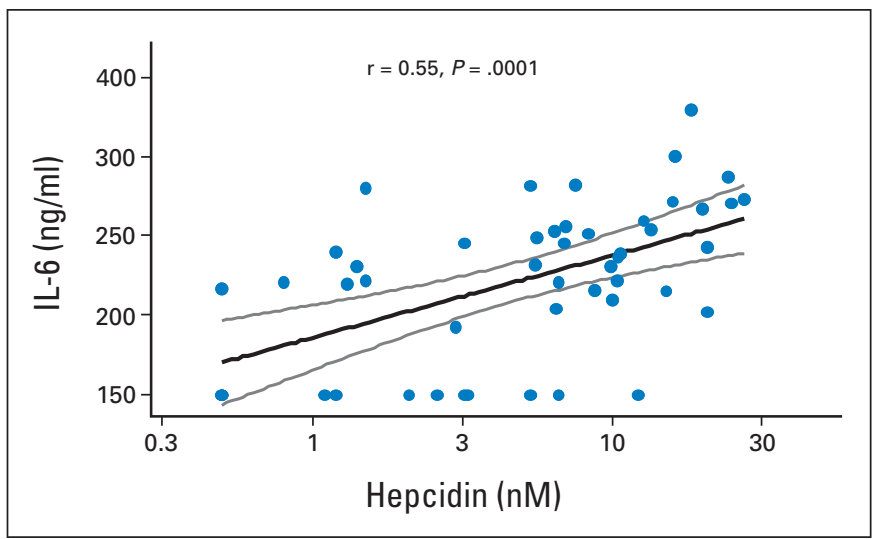

Fig 4. Correlation between hepcidin and cytokines. Scatter plot with linear regression (black line) and $95 \% \mathrm{Cls}$ (gray lines) shows significant correlation between hepcidin and interleukin 6 (IL-6). studies might address the relationship of IL-6, anemia, and hepcidin with prognosis in $\mathrm{HL}$ and whether these correlations will correct after therapy.

Elevated hepcidin levels in HL may also open a perspective for antihepcidin or anti-inflammatory therapy in reversing the anemia of inflammation in this disease. Administration of an anti-IL-6 receptor antibody tocilizumab in two patients with multicentric Castleman's disease rapidly lowered serum hepcidin levels and resulted in a prompt $\mathrm{Hb}$ increase even without iron administration. ${ }^{42}$

In conclusion, we propose the following scenario: HL disease activity is associated with production and release of IL- 6 into the systemic circulation, which stimulates the overproduction of hepcidin as an acute-phase reactant in the liver. Elevated levels of hepcidin in HL correlate with iron restriction and contribute to anemia. However, elevated hepcidin levels do not appear sufficient to induce anemia. Other hepcidin-independent mechanisms induced by pro-inflammatory cytokines, in particular IL-6, leading to anemia are likely to be involved.

\section{AUTHORS' DISCLOSURES OF POTENTIAL CONFLICTS OF INTEREST}

Although all authors completed the disclosure declaration, the following author(s) indicated a financial or other interest that is relevant to the subject matter under consideration in this article. Certain relationships marked with a " $U$ " are those for which no compensation was received; those relationships marked with a "C" were compensated. For a detailed description of the disclosure categories, or for more information about ASCO's conflict of interest policy, please refer to the Author Disclosure Declaration and the Disclosures of Potential Conflicts of Interest section in Information for Contributors. 
Employment or Leadership Position: Dorine W. Swinkels, Hepcidinanalysis.com (C) Consultant or Advisory Role: None Stock Ownership: None Honoraria: None Research Funding: None Expert Testimony: None Other Remuneration: None

\section{AUTHOR CONTRIBUTIONS}

Conception and design: Stefan Hohaus, Giuseppina Massini, Manuela Giachelia, Maria Teresa Voso, Giuseppe Leone

Financial support: Giuseppe Leone

Provision of study materials or patients: Stefan Hohaus, Giuseppina Massini, Manuela Giachelia, Barbara Vannata, Valentina Bozzoli, Annarosa Cuccaro, Francesco D’Alo', Luigi Maria Larocca
Collection and assembly of data: Stefan Hohaus, Giuseppina Massini, Manuela Giachelia, Barbara Vannata, Valentina Bozzoli, Annarosa Cuccaro, Francesco D'Alo'

Data analysis and interpretation: Stefan Hohaus, Giuseppina Massini, Reinier A.P. Raymakers, Dorine W. Swinkels, Maria Teresa Voso Manuscript writing: Stefan Hohaus, Giuseppina Massini, Luigi Maria Larocca, Reinier A.P. Raymakers, Dorine W. Swinkels, Maria Teresa Voso, Giuseppe Leone

Final approval of manuscript: Stefan Hohaus, Giuseppina Massini, Manuela Giachelia, Barbara Vannata, Valentina Bozzoli, Annarosa Cuccaro, Francesco D’Alo', Luigi Maria Larocca, Reinier A.P. Raymakers, Dorine W. Swinkels, Maria Teresa Voso, Giuseppe Leone

\section{REFERENCES}

1. Keel SB, Abkowitz JL: The microcytic red cell and the anemia of inflammation. N Engl $\mathrm{J}$ Med 361:1904-1906, 2009

2. Weiss G, Goodnough LT: Anemia of chronic disease. N Engl J Med 352:1011-1023, 2005

3. Bezwoda WR, Derman DP, Bothwell TH, et al: Serum ferritin and Hodgkin's disease. Scand $J$ Haematol 35:505-510, 1985

4. Dörner $M H$, Abel U, Fritze $D$, et al: Serum ferritin in relation to the course of Hodgkin's disease. Cancer 52:2308-2312, 1983

5. Means RT: Hepcidin and cytokines in anaemia. Hematology 9:357-362, 2004

6. Ganz T: Hepcidin, a key regulator of iron metabolism and mediator of anemia of inflammation. Blood 102:783-788, 2003

7. Ganz T: Hepcidin and its role in regulating systemic iron metabolism. Hematology Am Soc Hematol Educ Program 2006:29-35, 507

8. Nemeth E, Ganz T: Hepcidin and iron-loading anemias. Haematologica 91:727-732, 2006

9. Camaschella C, Silvestri L: New and old players in the hepcidin pathway. Haematologica 93: 1441-1444, 2008

10. Ganz $T$, Nemeth $E$ : Iron sequestration and anemia of inflammation. Semin Hematol 46:387 393, 2009

11. Kemna $E H$, Tjalsma $H$, Willems $H L$, et al: Hepcidin: From discovery to differential diagnosis. Haematologica 93:90-97, 2008

12. Nemeth $E$, Rivera $S$, Gabayan $V$, et al: IL-6 mediates hypoferremia of inflammation by inducing the synthesis of the iron regulatory hormone hepcidin. J Clin Invest 113:1271-1276, 2004

13. Kemna E, Pickkers $P$, Nemeth $E$, et al: Timecourse analysis of hepcidin, serum iron, and plasma cytokine levels in humans injected with LPS. Blood 106:1864-1866, 2005

14. Weiss G: Iron metabolism in the anemia of chronic disease. Biochim Biophys Acta 1790:682693, 2009

15. Wrighting DM, Andrews NC: Interleukin-6 induces hepcidin expression through STAT3. Blood 108:3204-3209, 2006

16. Verga Falzacappa MV, Vujic Spasic M, Kessler $\mathrm{R}$, et al: STAT3 mediates hepatic hepcidin expression and its inflammatory stimulation. Blood 109: 353-358, 2007

17. Pietrangelo $A$, Dierssen $U$, Valli L, et al: STAT3 is required for IL-6-gp130-dependent activation of hepcidin in vivo. Gastroenterology 132:294-300, 2007

18. Peyssonnaux $C$, Zinkernagel $A S$, Datta $V$, et al: TLR4-dependent hepcidin expression by myeloid cells in response to bacterial pathogens. Blood 107: 3727-3732, 2006

19. Skinnider BF, Mak TW: The role of cytokines in classical Hodgkin lymphoma. Blood 99:42834297, 2002

20. Casasnovas RO, Mounier N, Brice P, et al: Plasma cytokine and soluble receptor signature predicts outcome of patients with classical Hodgkin's Iymphoma: A study from the Groupe d'Etude des Lymphomes de I'Adulte. J Clin Oncol 25:1732-1740, 2007

21. Hohaus S, Giachelia M, Massini G, et al: Clinical significance of interleukin-10 gene polymorphisms and plasma levels in Hodgkin lymphoma. Leuk Res 33:1352-1356, 2009

22. Niens $M$, Visser $L$, Nolte $I M$, et al: Serum chemokine levels in Hodgkin lymphoma patients: Highly increased levels of CCL17 and CCL22. Br J Haematol 140:527-536, 2008

23. Hasenclever $D$, Diehl V: A prognostic score for advanced Hodgkin's disease. N Engl J Med 339: 1506-1514, 1998

24. Kroot JJ, Hendriks JC, Laarakkers CM, et al: (Pre)analytical imprecision, between-subject variability, and daily variations in serum and urine hepcidin: Implications for clinical studies. Anal Biochem 389: 124-129, 2009

25. Swinkels DW, Girelli D, Laarakkers $C$, et al: Advances in quantitative hepcidin measurements by time-of-flight mass spectrometry. PLoS One 3:e2706, 2008

26. Peters HP, Laarakkers $C M$, Swinkels DW, et al: Serum hepcidin-25 levels in patients with chronic kidney disease are independent of glomerular filtration rate. Nephrol Dial Transplant 25:848-853, 2010

27. Lou DQ, Lesbordes JC, Nicolas G, et al: Ironand inflammation-induced hepcidin gene expression in mice is not mediated by Kupffer cells in vivo. Hepatology 41:1056-1064, 2005

28. Macciò A, Madeddu C, Massa D, et al: Hemoglobin levels correlate with interleukin-6 levels in patients with advanced untreated epithelial ovarian cancer: Role of inflammation in cancer-related anemia. Blood 106:362-367, 2005

29. Sharma $\mathrm{S}$, Nemeth $\mathrm{E}$, Chen $\mathrm{YH}$, et al: Involvement of hepcidin in the anemia of multiple myeloma. Clin Cancer Res 14:3262-3267, 2008

30. Lee P, Peng H, Gelbart T, et al: Regulation of hepcidin transcription by interleukin-1 and interleukin-6. Proc Natl Acad Sci U S A 102:19061910, 2005

31. van Deuren $M$, Kroot JJ, Swinkels DW: Time-course analysis of serum hepcidin, iron and cytokines in a C282Y homozygous patient with Schnitzler's syndrome treated with IL-1 receptor antagonist. Haematologica 94:1297-1300, 2009

32. Nemeth E, Valore EV, Territo M, et al: Hepcidin, a putative mediator of anemia of inflammation, is a type II acute-phase protein. Blood 101:24612463, 2003

33. van Gameren MM, Willemse PH, Mulder $\mathrm{NH}$, et al: Effects of recombinant human interleukin-6 in cancer patients: A phase I-II study. Blood 84:14341441, 1994

34. Atkins MB, Kappler K, Mier JW, et al: Interleukin-6-associated anemia: Determination of the underlying mechanism. Blood 86:1288-1291, 1995

35. Ogawa M: Differentiation and proliferation of hematopoietic stem cells. Blood 81:2844-2853, 1993

36. Goicoechea M, Martin J, de Sequera P, et al: Role of cytokines in the response to erythropoietin in hemodialysis patients. Kidney Int 54:1337-1343, 1998

37. Graziadei I, Gaggl S, Kaserbacher R, et al: The acute-phase protein alpha 1-antitrypsin inhibits growth and proliferation of human early erythroid progenitor cells (burst-forming units-erythroid) and of human erythroleukemic cells (K562) in vitro by interfering with transferrin iron uptake. Blood 83: 260-268, 1994

38. Feelders RA, Vreugdenhil G, van Dijk JP, et al: Decreased affinity and number of transferrin receptors on erythroblasts in the anemia of rheumatoid arthritis. Am J Hematol 43:200-204, 1993

39. Ukarma L, Johannes $H$, Beyer U, et al: Hepcidin as a predictor of response to epoetin therapy in anemic cancer patients. Clin Chem 55:1354-1360, 2009

40. Vener C, Guffanti A, Pomati M, et al: Soluble cytokine levels correlate with the activity and clinical stage of Hodgkin's disease at diagnosis. Leuk Lymphoma 37:333-339, 2000

41. Biggar RJ, Johansen JS, Smedby KE, et al: Serum YKL-40 and interleukin 6 levels in Hodgkin Iymphoma. Clin Cancer Res 14:6974-6978, 2008

42. Kawabata $\mathrm{H}$, Tomosugi $\mathrm{N}$, Kanda $\mathrm{J}$, et al: Anti-interleukin 6 receptor antibody tocilizumab reduces the level of serum hepcidin in patients with multicentric Castleman's disease. Haematologica 92:857-858, 2007 